\title{
Stress oxidativo e dano oxidativo muscular esquelético: influência do exercício agudo inabitual e do treino físico
}

\author{
Filipe Ferreira \\ Rita Ferreira \\ José Alberto Duarte
}

https://doi.org/10.5628/rpcd.07.02.257
Centro de Investigação em Actividade Física, Saúde e Lazer

Faculdade de Desporto

Universidade do Porto

Portugal

\section{RESUMO}

A designação "espécies reactivas" (ER) é utilizada para englobar os radicais livres e outras moléculas, as quais, apesar de não possuírem átomos com electrões desemparelhados, são potencialmente geradoras desses radicais. Estas substâncias, naturalmente formadas em situações basais pelo metabolismo celular, são capazes, devido à sua elevada reactividade, de modificar a maioria das moléculas biológicas, colocando em risco a funcionalidade e a viabilidade celular. Particularmente a nível muscular esquelético, a mitocôndria parece constituir a principal fonte e, simultaneamente, o principal alvo das ER. No entanto, a Xantina Oxidase, a Fosfolipase A2, a desaminação das catecolaminas, assim como a infiltração tecidual pós-exercício de leucócitos, poderão contribuir também como fontes adicionais de ER nos músculos exercitados. A ocorrência e a intensidade do resultante dano oxidativo, tanto no músculo esquelético, como nos restantes órgãos e tecidos corporais, para além da taxa de síntese de ER, estão também dependente da capacidade antioxidante que o tecido expressa, quer à custa de antioxidantes endógenos, quer exógenos provenientes da dieta. Essa capacidade antioxidante depende não só do papel específico de cada um dos mecanismos antioxidantes, enzimáticos e não enzimáticos, como também da cooperação entre os mesmos. Como resultado do exercício físico agudo, as taxas de produção de ER de oxigénio aumentam, tal como o dano muscular causado por estes mesmos compostos. Contudo, com a repetição regular do exercício físico (treino), os resultados da literatura mostram que os músculos aumentam a sua capacidade antioxidante, tornando-os mais protegidos contra as ER formadas, não só em repouso, como também durante os exercícios agudos subsequentes.

Palavras-chave: radicais livres, espécies reactivas, antioxidantes, lesão oxidativa, exercício exaustivo, exercício regular

\begin{abstract}
Oxidative stress and damage in skeletal muscle:

Influence of unusual acute exercise and physical conditioning

The designation "reactive species" (RS) is currently used to classify the free radicals and other kind of molecules that despite not containing atoms with unpaired electrons are potentially producers of those radicals. These substances are naturally created at basal conditions by the cellular metabolism, and due to its high reactivity are able of modifying the structure of most of the biological molecules, placing in risk the cellular functionality and viability. Particularly in the skeletal muscle, the mitochondria seem to be the main source of RS and, simultaneously, the main target of these compounds. Xanthine Oxidase, the Phospholipase A2, the catecholamine deamination, as well as the tissue infiltration by leukocytes after exercise, may also contribute as additional sources of RS in exercised muscles. The occurrence and the intensity of the RS-induced oxidative damage in the skeletal muscle or in the remaining organs and tissues, behind the rate of RS synthesis, are also dependent of the antioxidant capacity of the tissue carried out by endogenous and exogenous substances. This antioxidant capacity, performed by enzymatic and non-enzymatic mechanisms, is dependent of the specific paper of each antioxidant and, moreover, also depends of the cooperation between them. As a consequence of the acute and unusual exercise, the production rate of RS of oxygen in skeletal muscle increases severely as well as the oxidative damage caused by these compounds. However, with the regular practice of physical exercise the recruited skeletal muscles increase their antioxidant capacity, becoming more protected against $R S$, not only at rest conditions but also during the subsequent practice of acute exercises.
\end{abstract}

Key-words: free radicals, reactive species, antioxidants, oxidative damage, exhaustive exercise, physical training 


\section{INTRODUÇÃO}

Hoje é unanimemente aceite que o exercício físico, quando praticado de forma regular, é determinante para a aquisição de um estilo de vida saudável, comportando-se como um agente terapêutico e/ou de prevenção para numerosas situações de morbilidade, com a consequente diminuição da mortalidade que lhes está associada $(18,75)$. No entanto, em franca oposição aos seus potenciais efeitos benéficos, o exercício físico agudo pode, sobretudo se inabitual e exaustivo, também induzir alterações orgânicas nefastas, especialmente quando os diferentes tecidos, órgãos ou sistemas não se encontram suficientemente adaptados para suportar, sem grandes alterações homeostáticas, os diferentes tipos de sobrecarga que lhes são exigidas $(75,92,99,100)$. De facto, para além do aumento do stress mecânico imposto, por exemplo, às fibras musculares esqueléticas solicitadas e às células dos sistemas osteo-articular e cardiovascular, também as elevações da temperatura corporal e da taxa metabólica, que se fazem sentir quer a nível muscular esquelético quer sistémico, ocorrem durante o exercício agudo $(99,100,101)$. Para além destas solicitações orgânicas, há cada vez mais evidências de que, durante o exercício físico agudo, tal como em qualquer outra situação que envolva um aumento súbito do metabolismo celular, ocorre também uma concomitante sobrecarga orgânica oxidativa, com a consequente lesão oxidativa $(7,29,31,36$, $41,49,67,82,89,92,93,95,98,111,117$ ), cuja magnitude parece ser dependente da intensidade, da duração e do tipo de exercício realizado(107). Esta sobrecarga oxidativa, normalmente designada por stress oxidativo, para além de se fazer sentir mais intensamente nos músculos esqueléticos, tem sido relatada também em muitos outros órgãos e sistemas corporais responsáveis pela regulação e manutenção da homeostasia orgânica $(7,8,10,17,29,64)$, cuja funcionalidade se encontra igualmente aumentada durante o exercício(99). Estando o stress oxidativo fortemente associado à fisiopatologia de numerosas patologias e doenças de carácter crónico/degenerativo, assim como às alterações degenerativas teciduais que caracterizam o envelhecimento orgânico(2, 15,51,52,53), poderá ser difícil, numa primeira análise, conciliar o incremento do stress oxidativo induzido pelo exercício agudo com os seus potenciais efeitos benéficos para a saúde de quem o pratica. Contudo, a prática regular de exercício físico (o treino físico), pode, quando eficazmente adaptado para cada indivíduo, aumentar a capacidade de defesa orgânica contra a ocorrência dessas lesões oxidativas em diferentes órgãos e tecidos corporais, dando uma maior protecção celular e tecidual aos indivíduos treinados, a qual se faz sentir quer em situações de repouso, quer durante a prática do exercício agudo $(41,61,62,65,84)$.

Com o presente trabalho pretende-se mostrar que as evidências quanto à ocorrência de stress oxidativo com o exercício físico e à influência do treino físico, não só não são contraditórias como se encontram em perfeita sintonia. Para esse fim, serão analisados nos músculos esqueléticos, especialmente em situações fisiológicas, quer seja em repouso, quer seja durante ou após o exercício agudo, as principais fontes de radicais livres e de espécies reactivas de oxigénio, as suas repercussões moleculares bem como os mecanismos de defesa antioxidante de que as fibras musculares estão munidas. Será também analisado o potencial efeito benéfico do treino físico na capacidade antioxidante muscular esquelética e as suas repercussões na magnitude do stress oxidativo e da lesão oxidativa, quer em situação de repouso, quer durante o exercício físico agudo.

\section{RADICAIS LIVRES VS. ESPÉCIES REACTIVAS}

Em 1954, a argentina Rebeca Gerschman sugeria, pela primeira vez, que os radicais livres (RL) eram agentes tóxicos e potencialmente geradores de condições patológicas ou de doenças (para refs. ver 46). Estes agentes constituem um grupo de substâncias químicas que se caracterizam por possuírem um ou mais electrões desemparelhados numa das suas orbitais externas $(32,43,51,61,102,110)$. É esta particularidade que lhes confere a reactividade e a instabilidade química que os caracterizam, tendendo a interagir com outras moléculas na sua proximidade, através da captação (comportando-se como oxidantes) ou da cedência (actuando como redutores) de electrões e/ou de átomos de hidrogénio(44, 109, 125). Deste modo, particularmente quando presentes em elevadas concentrações, eles podem induzir alterações severas na estrutura de moléculas fundamentais para a manutenção da homeostasia celular, resultando numa possível perda de funcionalidade ou até 
mesmo na perda de viabilidade da célula $(38,51,74,86)$. Contudo, para além desta potencial acção nefasta sobre a integridade e a funcionalidade das diferentes moléculas, os RL e outras substâncias com eles relacionadas, têm também sido responsabilizados pela regulação de importantes mecanismos fisiológicos, tais como a sinalização celular, a regulação da expressão de alguns genes $(32,66,85,124)$, a mediação da reacção inflamatória e a potenciação dos mecanismos de defesa orgânica, uma vez que fazem parte integrante do arsenal de armas letais leucocitárias (32, $56,102)$. A nível muscular esquelético, estas substâncias têm sido largamente estudadas, quer em situações de patologia ou de doença (local ou sistémica com repercussões musculares), quer em situações fisiológicas (em condição basal ou durante o exercício físico). Assim, é hoje unanimemente aceite que a taxa de produção de RL a nível muscular esquelético se encontra elevada em algumas situações de doença ou patologia $(28,37,51,114)$ e que, em indivíduos saudáveis, em situações fisiológicas, pode ser incrementada, comparativamente às situações de repouso, em função da intensidade, duração e tipo de exercício físico efectuado (107).

Os RL podem ser encontrados em grande quantidade na natureza associados aos átomos de carbono, enxofre, azoto e de oxigénio(51, 102), sendo classificados em função do átomo portador do(s) electrão(ões) desemparelhado(s) (Figura 1).

\begin{tabular}{|ll|}
\hline $\mathbf{R}_{\mathbf{3}} \mathbf{C} \cdot$ & Radicais livres de Carbono \\
$\mathbf{R}_{\mathbf{3}} \mathbf{N} \cdot$ & Radicais livres de Nitrogénio \\
$\mathbf{R}-\mathbf{O} \cdot$ & Radicais livres de Oxigénio \\
$\mathbf{R}-\mathbf{S} \cdot$ & Radicais livres de Enxofre \\
\hline
\end{tabular}

Figura 1. Classificação dos radicais livres de acordo com o átomo que contém o (s) electrão[ões] desemparelhado(s). Por norma, a existência destes electrões é assinalada na fórmula química da molécula com a colocação de um ponto $[\cdot]$ no átomo em causa, tal como assinalado na figura.

Todavia, os radicais livres de oxigénio (RLO), nomeadamente o radical superóxido $\left(\mathrm{O}_{2}{ }^{-}\right)$e o radical hidroxilo $(\mathrm{HO} \cdot)$, são aqueles que possuem uma maior relevância biológica, não só devido à sua elevada toxicidade, mas também pelo facto de serem os mais prevalentes nos organismos vivos que utilizam o oxigénio como comburente(51, 102). Existem, contudo, outras moléculas altamente reactivas e potencialmente tóxicas para o organismo, as quais, pelo facto de não conterem qualquer electrão desemparelhado nas suas orbitais, não se enquadram na definição de $\mathrm{RL}{ }^{(102)}$. Apesar de não serem verdadeiros radicais, estas moléculas, onde se incluem o peróxido de hidrogénio $\left(\mathrm{H}_{2} \mathrm{O}_{2}\right)$ e o ácido hipocloroso $(\mathrm{HOCl})$, são potenciais geradoras de RL e, por essa razão, as suas repercussões orgânicas, fisiológicas ou tóxicas, devem ser igualmente tidas em consideração(43, 51, 61, $74,102,109)$. Por essa razão, em detrimento da designação RL, passou a utilizar-se a designação "espécies reactivas", para englobar os RL e também essas moléculas que, apesar de não possuírem átomos com electrões desemparelhados, são potencialmente geradoras desses radicais (Figura 2). À semelhança do assumido para os RLO, as espécies reactivas de oxigénio (ERO) parecem ser aquelas com maior expressão e com maiores repercussões orgânicas, apesar de algumas espécies reactivas de nitrogénio poderem também desempenhar importantes funções na sinalização celular, quer em situações fisiológicas, quer patológicas(19).

\begin{tabular}{|c|c|c|}
\hline \multicolumn{3}{|c|}{ Espécies Reactivas de Oxigénio } \\
\hline Radicais: & \multicolumn{2}{|c|}{ Não-Radicais: } \\
\hline $\mathrm{O}_{2}-$ Superóxido $^{-}$ & $\mathrm{H}_{2} \mathrm{O}_{2}$ & Peróxido de hidrogénio \\
\hline OH Hidroxilo & $\mathrm{HOCl}^{-}$ & Hipoclorato \\
\hline $\mathbf{R O}_{2} \cdot$ Peroxilo & $\mathrm{O}_{3}$ & Ozono \\
\hline RO. Alcoxilo & ${ }^{1} \mathrm{O}_{2}$ & Singleto de oxigénio \\
\hline $\mathrm{HO}_{2} \cdot$ Hidroperoxilo & ONOO- & Peroxinitrito \\
\hline
\end{tabular}

Figura 2. Espécies reactivas de oxigénio, radicais e não radicais, potencialmente sintetizadas nos organismos que utilizam o ox igénio como comburente.

$\mathrm{O} \mathrm{O}_{2} \cdot$ - é a forma reduzida do oxigénio molecular formado através da captação de um electrão(32, 51, 74, 102). Esta molécula não consegue atravessar facilmente as membranas celulares, ficando normalmente confinada ao compartimento onde é produzida (habitualmente na matriz mitocondrial) (38). Pode, no entanto, desencadear uma série de reacções químicas com os ácidos gordos dos fosfolípidos e, dessa forma, comprometer a organização membranar, a 
qual é fundamental para o normal funcionamento celular( $(38,48,61,62,63,102)$. $\mathrm{O} \mathrm{O}_{2}{ }^{\circ-}$ pode sofrer dismutação, espontaneamente ou por acção enzimática, motivando a formação de $\mathrm{H}_{2} \mathrm{O}_{2}(32,44,74)$. Ao contrário do $\mathrm{O}_{2}{ }^{--}$, o $\mathrm{H}_{2} \mathrm{O}_{2}$ possui a capacidade de atravessar facilmente as membranas biológicas, apresentandose como a ERO menos reactiva da sua espécie e cuja estabilidade está dependente, entre outros factores, da presença de iões metálicos livres nas suas proximidades $(32,51,74,102)$. De facto, esta espécie pode comportar-se como um intermediário decisivo para a síntese de ERO mais reactivas, como o $\mathrm{HO}^{*}$, a partir da oxidação de metais de transição que se encontrem na sua forma livre, nomeadamente, o ferro $\left(\mathrm{Fe}^{2+}\right)$ e o cobre $\left(\mathrm{Cu}^{+}\right)(24,32,74,104)$. O principal metal de transição responsável pela transformação do $\mathrm{H}_{2} \mathrm{O}_{2}$ em $\mathrm{HO} \cdot$ é o $\mathrm{Fe}^{2+}$, através da reacção de Fenton, que ocorre, basicamente, através da reacção de um átomo de $\mathrm{Fe}^{2+}$ e uma molécula de $\mathrm{H}_{2} \mathrm{O}_{2}$, com a consequente produção de uma molécula de $\mathrm{HO}$ • (Figura 3). $\mathrm{O} \mathrm{Fe}^{3+}$ pode ser novamente reduzido a $\mathrm{Fe}^{2+}$, sob a acção do $\mathrm{O}_{2}{ }^{-}(51,102)$.

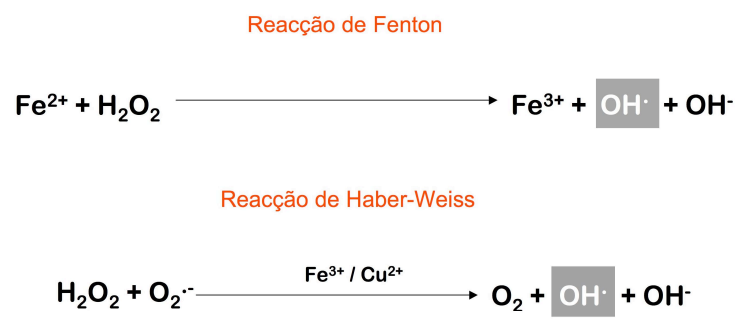

Figura 3. Reacções de Fenton e de Haber-Weiss, com a formação do radical hidroxilo.

$\mathrm{O} \mathrm{HO} \cdot$ possui uma elevada reactividade para com as biomoléculas adjacentes, sendo, provavelmente, a ERO que mais alterações estruturais induz nos sistemas biológicos $(61,74,102,109)$. Esta ERO, ao retirar um átomo de hidrogénio aos ácidos gordos poli-insaturados das membranas celulares, inicia o processo de peroxidação lipídica, com as consequentes alterações estruturais e funcionais membranares $(102,107,114)$. A reacção de uma ERO com uma outra molécula adjacente pode produzir uma ERO diferente, podendo, esta última, ser mais ou menos reactiva do que a ERO inicial. Este processo tende a repetir-se continuamen- te, terminando apenas quando a extremidade radical que contém o electrão desemparelhado formar uma ligação covalente com o electrão desemparelhado de outro radical $(32,80,102)$. As principais alterações estruturais e funcionais induzidas pelas ERO nos diferentes componentes orgânicos, assim como as suas consequentes repercussões na funcionalidade celular, estão ilustradas, de forma resumida, na figura 4 .

\section{FONTES DE PRODUÇÃO DE ERO}

Pelo simples facto de consumir oxigénio, o metabolismo celular, mesmo em situações basais, promove uma contínua formação de ERO, através da redução da molécula de oxigénio(15, 32, 41, 43, 58, 85, 86). Estas ERO podem ser produzidas em vários locais da célula, nomeadamente nas mitocôndrias, no retículo endoplasmático, nos lisossomas, nas membranas celulares, nos peroxissomas e no citosol $(2,15,72,74,85)$. Contudo, de todas as fontes referidas, a mitocôndria parece constituir a principal fonte de ERO no músculo esquelético, quer em repouso, quer durante o exercício agudo(2, 15, 16, 31, 72, 115). Estima-se que este organelo consuma cerca de $90 \%$ da totalidade do oxigénio utilizado pelo organismo, constituindo-se como a principal fonte de energia das células eucarióticas através da fosforilação oxidativa $(30,31,72,99)$. Neste processo, a mitocôndria utiliza a energia obtida nas transferências de electrões entre os complexos da cadeia de transporte de electrões (CTE) para bombear protões da matriz para o espaço intermembranar $(30,31,58)$. Deste processo, para além da criação de um gradiente electroquímico transmembranar (entre a matriz e o espaço intermembranar), originase também um produto final inócuo para as células: a água $(30,31,43,46,51,58)$. Todavia, o transporte de electrões na CTE pode não ser totalmente canalizado para o transporte transmembranar de protões e para formação de água, podendo haver uma pequena porção de electrões que reage directamente com o oxigénio molecular, conduzindo à formação de ERO (Figura 5) $(51,58,61,102)$. De acordo com a configuração electrónica da sua molécula, o oxigénio pode ser considerado um bi-radical uma vez que possui na sua orbital externa dois electrões desemparelhados com spins paralelos, sendo dessa forma considerada uma molécula potencialmente oxidativa pela sua tendência para captar electrões ${ }^{(80,85)}$. Assim, através 
da redução do oxigénio molecular com um, dois ou três electrões, origina-se, respectivamente, o $\mathrm{O}_{2}{ }^{--}$, o $\mathrm{H}_{2} \mathrm{O}_{2}$ ou o $\mathrm{HO} \cdot$ (Figura 5) (85).

Estima-se que cerca de 2 a $5 \%$ do oxigénio total consumido origine, por este processo, a síntese de ERO, particularmente nos complexos I e III $(46,58,74,87$, 121). Uma vez que taxa de formação destes compostos na mitocôndria parece ser proporcional à quantidade de oxigénio aí consumido por unidade de tempo, com o aumento da contracção muscular e com o consequente aumento da taxa do consumo de oxigénio, é aumentada também a taxa de síntese de ERO, agravando desse modo a agressão oxidativa muscular $(61,62$, $65,86,119)$. Como já referido, devido à sua elevada reactividade, as ERO são capazes de modificar a maioria das moléculas biológicas $(50,52,53$, $85,102)$. Por exemplo, a reacção do $\mathrm{HO}$ • com outras moléculas biológicas é bastante lesiva para a estrutura e funcionalidade celular, sendo responsável por alterações estruturais nas moléculas de ADN (reagindo, quer com as bases púricas, quer com as pirimídicas), nas proteínas e por destruição das membranas, fruto da sua reacção com os ácidos gordos poli-insaturados, dando origem a uma série de reacções em cadeia de peroxidação lípidica (Figura 4) $(58,74,80,112)$. A elevação de marcadores indirectos de peroxidação lipídica em mitocôndrias isoladas com perturbações homeostáti-

Oxigénio molecular

(2 electrões desemparelhados
Espécies reactivas de oxigénio

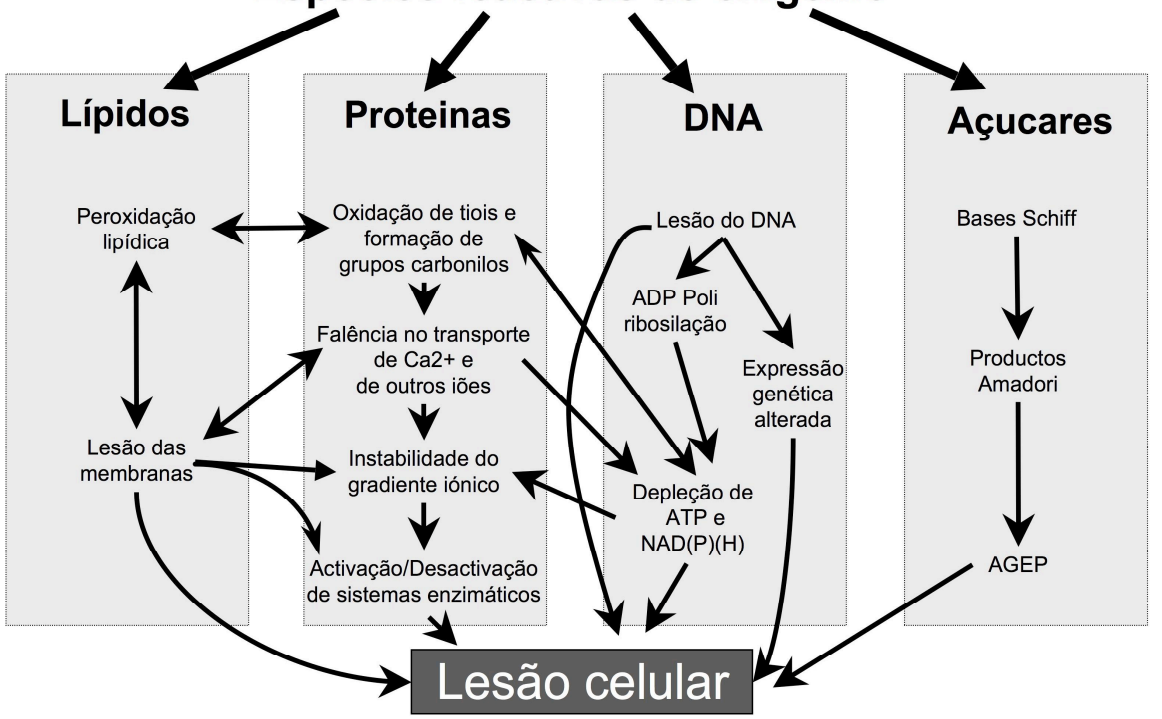

Figura 4. Mecanismos indutores de lesão celular motivados pela interacção das espécies reactivas de oxigénio com os diferentes componentes da célula (DNA - Ácido desoxirribonucleico; AGEP - Produtos de glicação avançada).

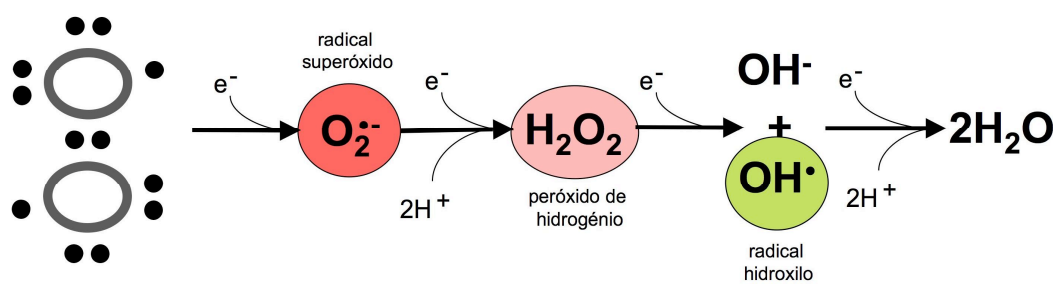
com spins paralelos na última orbital)

Figura 5. Distribuição dos electrões na orbital externa da molécula de oxigénio e redução da molécula a água, com o conjunto de reacções intermédias não enzimáticas que justificam a formação de espécies reactivas de oxigénio na cadeia de transporte de electrões.

cas, sugere que este organelo é, não só, o principal local de formação de ERO nas células em geral mas, possivelmente também, o maior alvo da acção nefasta destes compostos(80).

Apesar da mitocôndria se apresentar como o principal local de produção de ERO, existem, contudo, outras fontes celulares para a sua formação(15,72), estando algumas activas em condições fisiológicas basais, enquanto outras são activadas apenas em circunstâncias especiais, tais como durante o exercício físico exaustivo e inabitual $(2,3,23,26,44)$. À semelhança 
do verificado nas situações de isquemia/reperfusão muscular(3), supõe-se que a Xantina Oxidase (XO) possa também contribuir para a exagerada produção tecidual de ERO motivada pelo exercício físico agudo(20, 32, 34, 49, 54, 55). Esta enzima está presente em grandes quantidades no endotélio vascular dos músculos esqueléticos e é responsável pela conversão da Hipoxantina em Xantina e esta em Ácido Úrico (Figura 6) (20, 91, 122). Apesar da designação, a XO, in vivo, e em condições homeostáticas, actua quimicamente como uma desidrogenase, utilizando a Nicotinamida Adenina-dinucleótido (NAD ${ }^{+}$) como receptor de átomos de hidrogénio. No entanto, em circunstâncias especiais, tais como as que ocorrem em situações de isquemia/reperfusão ou durante o exercício físico agudo exaustivo, a XO pode converter-se, por acção proteolítica, numa oxidase oxigénio-dependente, passando a utilizar o oxigénio adjacente como receptor de electrões, motivando, assim, a formação de ERO (Figura 6) (20, 34, 49, 55, 91). Na base desta alteração funcional da XO pensa-se estar a activação das calpaínas, uma família de proteases citoplasmáticas especialmente estimuladas pela elevação térmica tecidual e/ou pelas elevadas concentrações intracelulares do ião cálcio na sua forma livre $(20,54,59,91)$. A conversão da XO, da forma de desidrogenase para a forma de oxidase oxigéniodependente, associada a situações de grande disponibilidade dos substratos desta enzima, decorrentes do facto da elevada taxa de utilização de Adenosina Trifosfato (ATP) ser, pelo menos nos momentos de ajuste metabólico, superior à sua taxa de resíntese (99), constituem situações propícias para a síntese adicional de ERO no músculo esquelético exercitado (Figura 6) $(20,54,55,59)$.

Também a Fosfolipase A2 (PLA2) muscular, particularmente activada durante o exercício físico, poderá constituir outra fonte importante para a produção de $\operatorname{ERO}(4,59,61,76)$. Esta enzima, localizada no sarcolema, na membrana dos diferentes organelos, no sarcoplasma e no interior dos lisossomas, utiliza os fosfolípidos das membranas para a síntese de Ácido Araquidónico, o qual é substrato para a acção subsequente da Ciclo-oxigenase e da Lipo-oxigenase motivando a formação de prostaglandinas, leucotrienos, tromboxanos e, concomitantemente, ERO(76). Se, por um lado, a PLA2 parece ter algum papel protec- tor nas membranas celulares, pela remoção dos hidroperóxidos resultantes da peroxidação lipídica, por outro, os lisofosfolípidos e o ácido araquidónico resultantes da acção desta enzima, têm um efeito detergente nas membranas celulares podendo, assim, motivar a perda da permeabilidade selectiva do sarcolema, favorecendo a perda da homeostasia celular ao ião cálcio e a difusão de compostos sarcoplasmáticos para o espaço intercelular(4, 32, 67, 76). Este fenómeno poderá explicar a forte correlação, descrita em humanos, entre a concentração sérica de substâncias reactivas ao ácido tiobarbitúrico

(TBARS), um marcador indirecto de peroxidação lipídica, e a actividade plasmática da Creatina Kinase (CK) após situações de exercício agudo exaustivo(90). São muitas as evidências do aumento da actividade da PLA2 durante e/ou após o exercício físico agudo. Por exemplo, Symons et al.(113) demonstraram a acumulação de prostaglandina E2 (PGE2) no músculo esquelético após um breve período de electro-estimulação e, também em situação de estimulação mecânica passiva, Vandenburgh et al.(116) observaram nas fibras musculares um aumento da produção de PGE2 e da proteólise tecidual(para mais refs. ver 6).

Não é, por isso, de surpreender que, após a realização de um exercício físico, particularmente se este for inabitual, efectuado com elevada intensidade e/ou com elevada percentagem de contracções excêntricas, se observem alterações degenerativas das células musculares nos músculos exercitados, quer em animais de laboratório, quer em humanos (Figura 7) (para refs. ver 4, 6, 38, 62, 119).

Muitos trabalhos têm sugerido que entre as causas destas alterações degenerativas, para além da excessiva tensão exercida sobre os sarcómeros(79) e do aumento da temperatura corporal, esteja também a lesão oxidativa tecidual motivada pela produção exagerada de $\operatorname{ERO}(36,79,82)$. Estas situações favorecem a desregulação homeostática ao ião cálcio, a qual é especialmente sensível à acção das ERO, seja pelo facto destas interagirem negativamente com a actividade de muitas enzimas envolvidas no metabolismo daquele ião, nomeadamente as AT Pases transportadoras de cálcio(47, 121), seja pelo facto de induzirem disfunção membranar por peroxidação lipídica $(51,58)$. Ao criar condições favoráveis à acumulação intracelular exagerada e pro- 


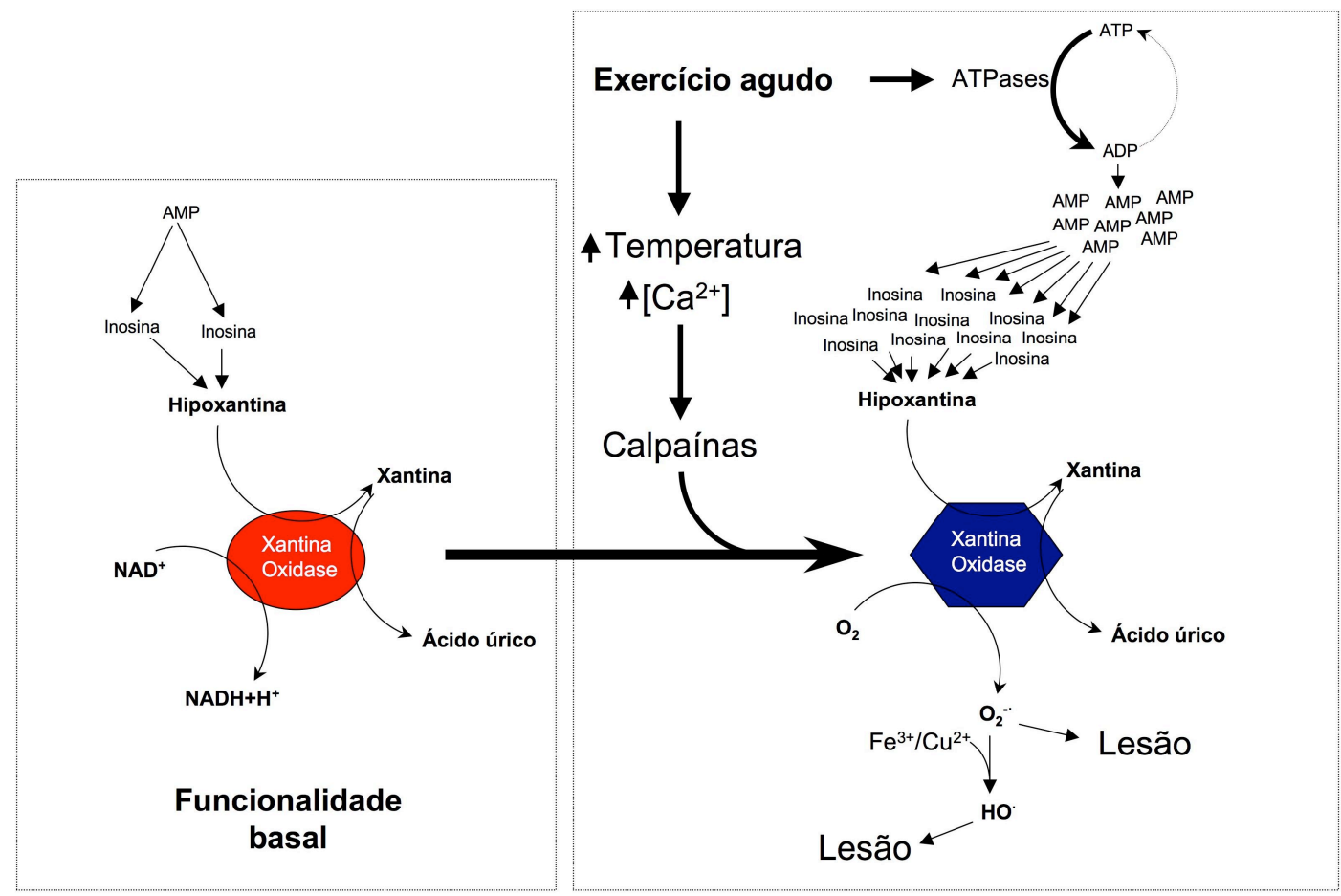

Figura 6. Produção de espécies reactivas de oxigénio pela Xantina Oxidase durante o exercício agudo (NADPH/NADP $P^{+}$Formas reduzida e oxidada da Nicotinamida Adenina-dinucleótido; ATP - Adenosina Trifosfato; ADP - Adenosina Difosfato; AMP - Adenosina Monofosfato).

Figura 7. Fotografia de microscopia óptica de um corte transversal do músculo soleus de ratinho sacrificado 24 horas após um exercício físico exaustivo. Paro além do alargamento do espaço intersticial, é notória uma área de necrose com infiltração adjacente de fagócitos, sugerindo a presença de uma reacção infla-

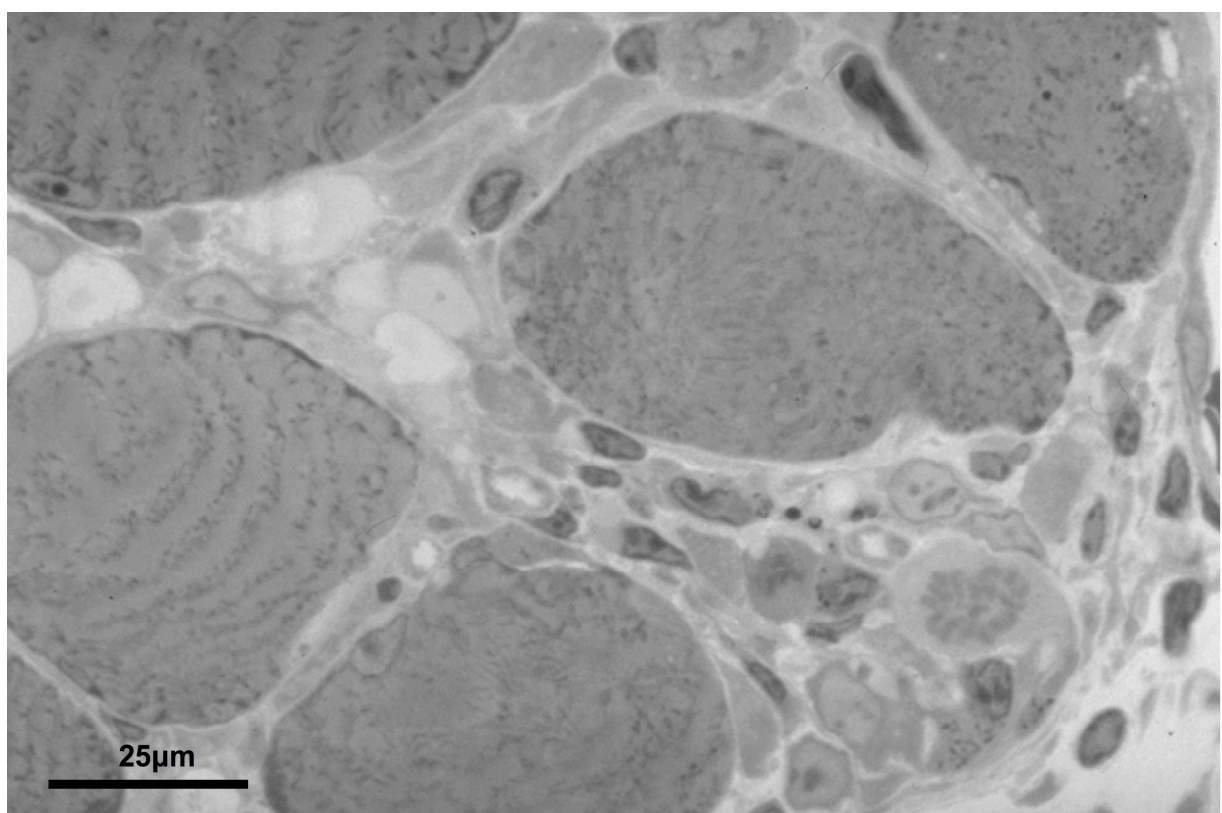
matória muscular. 
longada do ião cálcio livre nas fibras musculares, o exercício físico excessivo pode, assim, induzir uma activação de enzimas proteolíticas dependentes do ião cálcio, as quais poderão comprometer a viabilidade das células ou, como no caso das fibras musculares, de algumas das suas áreas ${ }^{(47)}$. Assim, para além da hipotética contribuição dos detritos celulares, resultantes destes processos degenerativos motivados pelo exercício( ${ }^{(4,33)}$, também os leucócitos que posteriormente se infiltram no tecido podem ser uma importante fonte muscular adicional de produção de ERO, contribuindo, dessa forma, para a agressão oxidativa associada ao aumento agudo da actividade muscular $(33,54,55,59)$, especialmente algumas horas após o término do exercício(33). Um a três dias após o exercício agudo, a resposta inflamatória nos músculos agredidos parece estar completamente estabelecida ${ }^{(4,}$ 33), com alguns polimorfonucleares e numerosos mononucleares dispersos pelo endomísio e no interior de algumas fibras lesadas(4). Para além dos trabalhos realizados com animais de laboratório, a infiltração muscular de leucócitos tem também sido descrita em humanos, particularmente após exercícios realizados com grande percentagem de contracções excêntricas $(40,82,83)$. De facto, durante a resposta de fase aguda, os neutrófilos são atraídos para a área lesada, libertando enzimas lisossómicas e $\operatorname{ERO}(32,54,59,83)$. Na presença de agentes perturbadores da estabilidade da membrana citoplasmática dos neutrófilos, é estimulada a produção de $\mathrm{O}_{2} \cdot-$ por acção da enzima NADPH Oxidase ${ }^{(54,59)}$, a qual, na presença de Adenosina Difosfato (ADP) e $\mathrm{Fe}^{3+}$, cataliza a transferência de um electrão da forma reduzida da Nicotinamida Adenina-dinucleótido Fosfato $\left(\mathrm{NADPH}+\mathrm{H}^{+}\right)$para o $\mathrm{O}_{2}$, dando origem à formação do radical superóxido ${ }^{(16)}$. Para além do $\mathrm{O}_{2}{ }^{\bullet-}$, os neutrófilos têm sido também referidos como fonte de um conjunto de outras ER, incluindo o $\mathrm{H}_{2} \mathrm{O}_{2}$ e o $\mathrm{HOCl}$, as quais se têm mostrado decisivas para um eficaz combate a agentes patogénicos invasores (Figura 8$)(54,59)$. Tendo em consideração os tempos de maior ou menor actividade das fontes de ERO atrás referidas, a figura 9 ilustra, de forma grosseira, a hipotética contribuição relativa de cada uma dessas fontes, durante e após o exercício físico agudo(4, 33, 34).

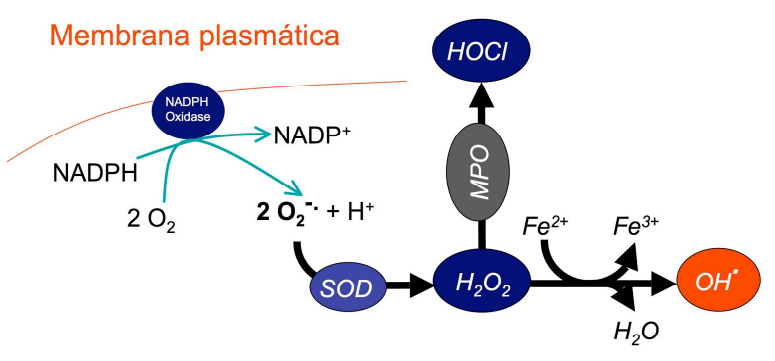

Figura 8. Vias de produção de espécies reactivas de oxigénio pelos fagócitos que infiltram o tecido (SOD - Superoxido Dismutase; MPO - Mieloperoxidase; $\mathrm{NADPH} / \mathrm{NADP}^{+}$- Formas reduzida e oxidada da Nicotinamida Adenina-dinucleótido Fosfato].

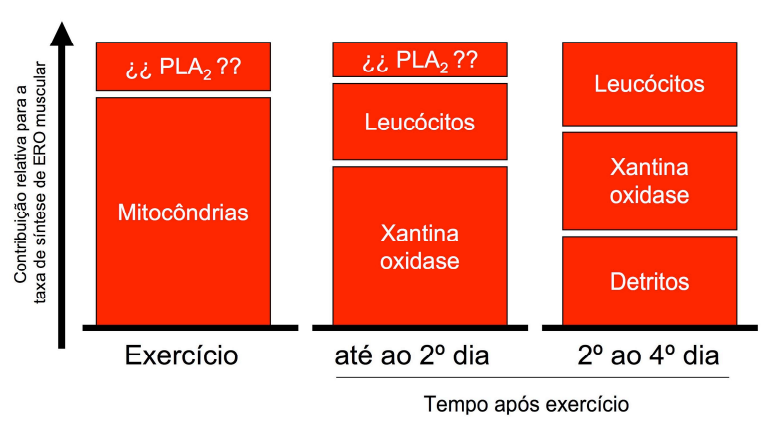

Figura 9. Hipotética contribuição relativa das principais fontes musculares esqueléticas de produção de espécies reactivas de oxigénio durante e após o exercício físico agudo (PLA2 - Fosfolipase A2).

Um outro possível mecanismo de formação de ERO durante a contracção muscular esquelética pode estar relacionado com a oxidação das catecolaminas circulantes $(23,35)$. Estas hormonas são normalmente inactivadas in vivo de duas formas: i) ou por via enzimática, pela acção da Monoamina Oxidase (MAO) e da Catecol-O-Metiltransferase (COMT), ou então ii) por via não enzimática, pela sua própria auto-oxidação, que ocorre normalmente quando as vias enzimáticas estão saturadas(121). Por cada molécula oxidada pela MAO origina-se uma molécula de $\mathrm{H}_{2} \mathrm{O}_{2}$. $\mathrm{Na}$ sua auto-oxidação, a formação de derivados quinónicos, a partir das catecolaminas, leva também à formação de $\operatorname{ERO}^{(23,42,91,121)}$. Assim, como resultado do aumento da estimulação do sistema nervoso autónomo simpático, durante o exercício físico agudo há um aumento das concentrações de catecolaminas circulantes, o qual parece ser proporcional à intensidade do exercício efectuado( ${ }^{(99)}$. Esta situação motiva o incremento da taxa de oxidação das aminas 
biogénicas, podendo resultar numa formação acrescida de ERO, em particular de $\mathrm{H}_{2} \mathrm{O}_{2}$. Resultados experimentais sugerem que o metabolismo destas aminas também pode ocorrer no músculo esquelético(35), especialmente em situações onde as suas concentrações séricas estão elevadas, tal como ocorre durante o exercício físico agudo, uma vez que a inibição da MAO pela pargilina, motiva uma diminuição acentuada da taxa de produção muscular de $\mathrm{H}_{2} \mathrm{O}_{2}$. Para além da MAO e à semelhança do ocorrido noutros tecidos, é possível que outros sistemas enzimáticos possam também participar activamente na produção de $\mathrm{H}_{2} \mathrm{O}_{2}$ no músculo esquelético em situações basais e durante o exercício físico $(1,74,123)$. Contudo, nestas situações fisiológicas, acredita-se que a dismutação do $\mathrm{O}_{2} \cdot-$, de forma espontânea ou por acção da superóxido dismutase (SOD), deva ser a mais importante fonte de produção de $\mathrm{H}_{2} \mathrm{O}_{2}$ no músculo esquelético( ${ }^{74)}$.

\section{SISTEMA DE DEFESA ANTIOXIDANTE}

Devido ao elevado potencial de toxicidade do oxigénio e à sua grande utilização pelos organismos aeróbios, torna-se necessário que estes estejam suficientemente munidos de uma diversidade de sistemas antioxidantes para proteger as suas células dos efeitos nocivos das ERO(14, 38, 70, 74). Com o aumento agudo da taxa de produção de ERO, não só nos músculos recrutados mas também no organismo em geral, o exercício físico pode estar a comprometer, a longo prazo, a funcionalidade dos diferentes órgãos e sistemas e, dessa forma, a longevidade dos indivíduos que o praticam(86). Contudo, apesar da lógica deste pressuposto, numerosos trabalhos realizados com Drosophila, submetidas ao exercício físico regular, e com ratos, submetidos a restrição calórica e inactividade física, têm evidenciado um efeito benéfico notório da actividade física regular, quer na longevidade dos animais quer nos marcadores de lesão oxidativa tecidual em situações basais e de exercício agudo (para refs. ver 80, 86, 119). De facto, o aumento, em situações basais, da actividade dos sistemas celulares de defesa directamente relacionados com a inactivação das ERO, parecem constituir adaptações crónicas induzidas por um período prévio de treino físico, as quais atenuam a agressividade das ERO para com as estruturas biológicas $(17,86)$. Tais adaptações parecem conferir às células uma maior resistência ao potencial efeito nefasto das ERO, não só para as que são formadas normalmente em repouso, atenuando assim as lesões oxidativas diárias e, hipoteticamente, os fenómenos degenerativos associados ao envelhecimento orgânico $(2,15)$, mas também para aquelas originadas mais intensamente pelo exercício agudo, protegendo os atletas da sobrecarga oxidativa induzida pelos seus exercícios diários e, dessa forma, favorecendo a sua recuperação orgânica $(24,41,99,100)$. Um antioxidante é, por definição, qualquer substância que, quando presente em baixas concentrações relativamente às dos potenciais substratos oxidáveis, atrasa significativamente, ou inibe, a oxidação desses substratos pelas ERO(32, 51, 110). Estas substâncias possuem a capacidade de fornecer electrões/átomos de hidrogénio às ERO sem se transformarem em moléculas instáveis. Os mecanismos de defesa antioxidante nos diferentes tecidos compreendem sistemas enzimáticos e não enzimáticos( ${ }^{(48)}$ e podem ser classificados em função do seu mecanismo de acção predominante (antioxidantes de prevenção, de intercepção e de reparação), da sua localização orgânica (antioxidantes intracelulares e extracelulares) e da sua proveniência, seja da dieta (antioxidantes exógenos), seja da síntese endógena (antioxidantes endógenos) (Tabela 1). Os antioxidantes de prevenção são aqueles que criam condições favoráveis para evitar a formação de ERO, e dos quais são exemplos as proteínas que se ligam aos iões metálicos de transição, prevenindo a sua presença na forma livre ou, então, as enzimas responsáveis pela manutenção do equilíbrio redox da célula e pela redução de antioxidantes de intercepção previamente oxidados, como é o caso da glutationa; o zinco e o selénio, provenientes da dieta, apesar de não terem, por si só, uma acção antioxidante directa, estão englobados no grupo dos antioxidantes de prevenção porque são imprescindíveis para a correcta funcionalidade de algumas enzimas antioxidantes; os antioxidantes de intercepção são todos aqueles que reagindo directamente com as ERO, as transformam em substâncias menos reactivas ou até não reactivas, impedindo dessa forma o seu ataque às estruturas celulares; os antioxidantes de reparação favorecem a remoção dos danos moleculares causados pelas ERO e a reconstituição da estrutura e da homeostasia celular $(32,45,60)$. 
Tabela 1. Origem (endógena ou exógena), localização (intracelular ou extracelular) e mecanismos de acção (prevenção, intercepção ou reparação) dos principais antioxidantes orgânicos.

\begin{tabular}{|c|cc|}
\hline \multicolumn{2}{|c|}{ Antioxidantes Exógenos } & \multicolumn{2}{c|}{ Antioxidantes Endógenos } \\
\hline Prevenção & Extracelulares & Intracelulares \\
Zinco & Prevenção & Prevenção \\
Selénio & Albumina & Glutationa Peroxidase \\
& Bilirrubina & Superóxido Dismutase \\
& Ceruloplasmina & Catalase \\
Intercepção & Ferritina & Glutationa Redutase \\
Ácido Ascórbico & Mioglobina & \\
Alfa-tocoferol & Metalotioneína & Intercepçã o \\
Carotenoides & Haptoglobina & Glutationa \\
& & Ácido Úrico \\
& & Coenzima Q \\
& & Reparação \\
& & Metaloenzimas \\
\hline
\end{tabular}

No interior da célula, a eliminação dos compostos reactivos, efectuada quer por antioxidantes exógenos, quer endógenos, constitui um pré requisito para a sobrevivência celular, sendo normalmente efectuada por: 1) sistemas enzimáticos, englobados nos antioxidantes classificados de prevenção, tais como a SOD, a Catalase (CAT) e a Glutationa Peroxidase (GPx); 2) moléculas que neutralizam os radicais no meio aquoso, classificadas como antioxidantes de intercepção, como o Ascorbato, Urato e a Glutationa reduzida (GSH); 3) moléculas que neutralizam os radicais no interior das membranas, classificadas como antioxidantes de intercepção, como os Tocoferois, Flavonoides, Carotenoides e Ubiquinol; 4) enzimas envolvidas na redução de formas oxidadas de pequenos antioxidantes moleculares, também consideradas antioxidantes de prevenção, tais como, a Glutationa Redutase (GR), a Dihidroascorbato Redutase (DR) ou aqueles que são responsáveis pela manutenção dos grupos tiol das proteínas, como a Tioredoxina Redutase (TR); e 5) mecanismos celulares que mantêm um meio reduzido, nomeadamente, a Glucose-6-fosfato Desidrogenase, que regenera a forma oxidada da Nicotinamida Adenina-dinucleótido Fosfato $(15,51,74,108,110)$. Destes, os agentes que apresentam um papel mais preponderante dentro dos sistemas intracelulares de defesa antioxidante

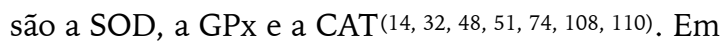

situações de produção exagerada de ERO, cada uma destas enzimas possui a capacidade de catalizar reacções que conduzem à produção de espécies menos reactivas ou de neutralizar metabolitos do oxigénio reactivo(100). A capacidade antioxidante de um organismo depende não só do papel específico de cada mecanismo antioxidante, como também da cooperação entre os mesmos (Figuras 10 e 11). A forma como as defesas se complementam difere não só entre os organismos ou tecidos, mas também entre os compartimentos celulares(108). Não parece pois haver dúvidas de que, para além da taxa de produção de ERO, o nível de lesão celular oxidativa motivada pelas ERO está também intimamente dependente da capacidade de defesa orgânica dos diferentes agentes antioxidantes de prevenção ou de intercepção, assim como da capacidade celular de reparação do hipotético dano sofrido.

\section{Mecanismos enzimáticos}

A GPx tem um papel determinante nos mamíferos e nos processos de neutralização das $\operatorname{ERO}^{(14,86)}$ pois é considerada a enzima mais importante para a oxidação do $\mathrm{H}_{2} \mathrm{O}_{2}$ a água(74). A GPx dos mamíferos tem uma maior afinidade pelo $\mathrm{H}_{2} \mathrm{O}_{2}$ do que a CAT, o que significa que em concentrações baixas de $\mathrm{H}_{2} \mathrm{O}_{2}$, a GPx apresenta um papel muito mais activo na sua remoção celular $(74,85,103)$. O seu correcto funciona- 
mento está dependente da presença de selénio na sua constituição e da disponibilidade de $\mathrm{H}_{2} \mathrm{O}_{2}$ e de outros hidroperóxidos, utilizando a GSH como dador de electrões/hidrogénios, formando Glutationa oxidada (GSSH) e água (Figura 10) $(14,51,85,86,120,125)$. Este funcionamento atribui à GPx um papel importante na protecção celular das membranas lipídicas, proteínas e ácidos nucleicos contra os ERO(86). Contrastando com a sua elevada actividade noutros órgãos, nos músculos esqueléticos dos mamíferos a actividade da GPx é muito reduzida(51) e varia em função do tipo de fibra muscular, sendo as fibras com características mais oxidativas, em oposição às fibras glicolíticas, aquelas que apresentam uma maior actividade desta enzima ${ }^{(98)}$.

A GPx celular distribui-se pela mitocôndria e pelo citosol(86). No músculo-esquelético, aproximadamente $45 \%$ da actividade da GPx é encontrada no citosol, estando os restantes $55 \%$ na mitocôndria ${ }^{(63)}$. Esta localização mitocondrial e citoplasmática da GPx permite a sua proximidade às diversas fontes de formação de hidroperóxidos, fazendo desta enzima um dos principais neutralizadores de hidroperóxidos provenientes das diferentes fontes celulares(86). A mitocôndria possui dois tipos de enzimas com a função de peroxidase, a GPx clássica e a GPx dos hidroperóxidos lipídicos, sendo esta a única enzima intracelular capaz de reduzir directamente os hidroperóxidos de fosfolípidos e colesterol das membranas( ${ }^{(5)}$. Devido ao facto da GSH ser oxidada pela GPx convertendo-se em GSSG, as células deverão possuir uma via de regeneração de GSH. Esta reacção é catalisada pela enzima GR, que utiliza a Nicotinamida Adenina-dinucleótido Fosfato na sua forma reduzida (NADPH) como cofactor, transformando a GSSG novamente em GSH $(32,51)$. Os níveis intracelulares de GSH estão, deste modo, dependentes da interacção das enzimas GPx e GR, bem como dos mecanismos de resíntese intracelular e de captação de GSH a partir do meio extracelular (Figura 11) (98). Por seu lado, a GR não possui características antioxidantes directas, sendo porém muito importante para o normal funcionamento do sistema antioxidante( ${ }^{(86)}$, uma vez que a funcionalidade da GPx está dependente dos níveis de GSH como dador de hidrogénios/electrões (Figura 10). Para além disso, a presença de GSH em quantidades adequadas é também determi- nante para a manutenção da homeostasia orgânica, tendo em consideração a sua participação na síntese de ADN e proteínas, na actividade de numerosas enzimas intracelulares, na libertação de neurotransmissores no sistema nervoso e na eliminação hepática de compostos carcinógenicos $(16,32)$. Em condições fisiológicas normais, a GR mantém mais de $98 \%$ da GSH intracelular no estado reduzido, contribuindo, assim, para a manutenção do meio intracelular em estado reduzido( ${ }^{(98)}$. Para além da GPx, a redução dos hidroperóxidos orgânicos com recurso à GSH pode também ser catalisada por uma enzima independente do selénio, a Glutationa-S-Transferase (GST), a qual pode actuar, quer como uma peroxidase, quer como uma transferase $(103,109,120)$. A actividade da GPx parece ser particularmente importante na redução de hidroperóxidos orgânicos, enquanto que a actividade da GST parece amplamente envolvida na eliminação de compostos, particularmente a nível hepático, através da conjugação com a glutationa(51). A SOD, como já referido, metaboliza o $\mathrm{O}_{2}{ }^{--}$com formação de $\mathrm{H}_{2} \mathrm{O}_{2}$ (Figura 10) $(74,85,86)$. Nos mamíferos, existem três isoenzimas da SOD, codificadas e reguladas de forma independente: a citosólica $(\mathrm{Cu}, \mathrm{Zn}$ SOD ou SOD1), a mitocondrial (Mn-SOD ou SOD2) e uma forma extracelular da $\mathrm{Cu}, \mathrm{Zn}$-SOD ou (SOD3) $(44,105)$. A actividade da SOD total no músculo esquelético é inferior à do fígado e do rim, semelhante à do cérebro, coração e pâncreas e superior à dos eritrócitos (para refs. ver 51). No músculo-esquelético, 15 a $35 \%$ da actividade total da SOD está localizada nas mitocôndrias, estando as restantes 65 a $85 \%$ no citosol(77). A actividade total desta enzima varia também com as características histoquímicas do músculo-esquelético, sendo os músculos com maior percentagem de fibras oxidativas aqueles que evidenciam uma maior percentagem desta enzima, comparativamente aos músculos com menor capacidade oxidativa $(25,98)$.

A CAT é uma enzima presente na maioria dos organismos aeróbios e é responsável pela conversão do $\mathrm{H}_{2} \mathrm{O}_{2}$ intracelular em água e oxigénio (Figura 10) (57, $74,81,86,97)$, estando a maior parte da actividade desta enzima localizada nos peroxissomas, tanto nos tecidos animais como nas plantas(51). As mitocôndrias e o retículo endoplasmático contêm também alguma actividade da CAT, embora muito reduzida, pelo que 
qualquer $\mathrm{H}_{2} \mathrm{O}_{2}$ formado in vivo nestes organelos não deverá ser degradado expressivamente por esta via(51, 62). Na generalidade dos animais, a CAT está presente em praticamente todos os órgãos, estando particularmente concentrada no fígado e nos eritrócitos(51). O cérebro, o coração, e os músculos esqueléticos contêm pequenas quantidades, porém, a sua actividade é muito variável nos diversos músculos e em diferentes regiões do mesmo músculo(51). Tal como a SOD e a GPx, a actividade da CAT é mais elevada nos músculos com predominância de fibras oxidativas e mais reduzida nos músculos com uma grande percentagem de fibras glicolíticas( ${ }^{(98)}$.

Pelo exposto, fica claro que o organismo possui a capacidade de oxidar o $\mathrm{H}_{2} \mathrm{O}_{2}$ a água, através de reacções catalizadas por duas enzimas: a CAT e a GPx ${ }^{(57)}$. Esta conversão é efectuada predominantemente pela GPx, estando a contribuição relativa desta enzima na dependência das concentrações de $\mathrm{H}_{2} \mathrm{O}_{2}{ }^{(57)}$. De facto, a partir do momento em que a taxa de $\mathrm{H}_{2} \mathrm{O}_{2}$ se eleva, podendo esta molécula constituir de substrato, via reacção de Fenton, para formar o $\mathrm{HO}^{\bullet}$, acredita-se que a CAT adquira um papel importante como um mecanismo adicional de defesa antioxidante celular, limitando a acumulação intracelular de $\mathrm{H}_{2} \mathrm{O}_{2}$ (57).

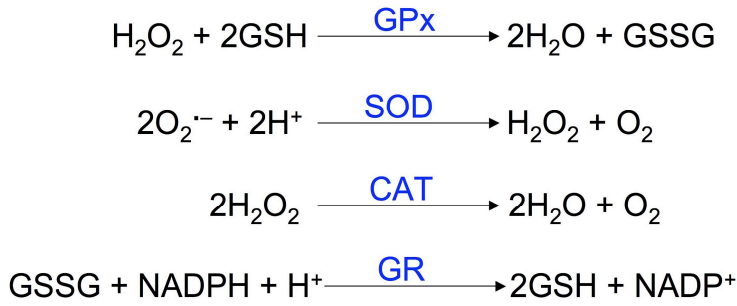

Figura 10. Reacções catalizadas pelas enzimas antioxidantes (GPX Glutationa Peroxidase; SOD - Superóxido Dismutase; CAT - Catalase; GR Glutationa Redutase; GSH e GSSG - Formas reduzida e oxidada da Glutationa; $\mathrm{NADPH}$ e $\mathrm{NADP}^{+}$- Formas reduzida e oxidada da Nicotinamida Adenina-dinucleótido Fostato].

No que respeita à influência imediata do exercício físico agudo sobre a actividade destas enzimas antioxidantes, os resultados da literatura são confusos e muitas vezes contraditórios (14,70, 84), havendo necessidade de estudos adicionais esclarecedores daquele efeito no tecido muscular esquelético. De facto, ape- sar de se esperar que, devido à oxidação das proteínas musculares pelas elevadas taxas de formação de $\operatorname{ERO}(21,71,96)$, a actividade enzimática em geral pudesse ficar negativamente afectada, com diminuição simultânea da funcionalidade das diferentes enzimas antioxidantes, nem todos os trabalhos experimentais o têm revelado(82). Independentemente do potencial efeito negativo imediato sobre a capacidade antioxidante, é consensual que algumas ERO, particularmente $\mathrm{o}_{2} \mathrm{O}_{2}$, desempenham um importante papel na indução celular da expressão de numerosos genes, entre os quais se encontram os responsáveis pela síntese das enzimas antioxidantes (para mais refs. ver $14,65,66,80,88,107$ ). Assim, com o treino físico, à medida que os picos de produção de ERO motivados pelo exercício agudo se vão sucedendo no tempo, será de esperar que a taxa de síntese dos antioxidantes vá também aumentando, proporcionando às células uma maior capacidade de defesa contra esse tipo de situações agudas futuras $(84,111)$. Por essa razão, a quantificação da actividade das enzimas antioxidantes em situações basais tem também permitido, de forma indirecta, inferir sobre o nível de agressão oxidativa a que o músculo foi sujeito em cada exercício agudo efectuado(71). Os resultados da literatura são consensuais quanto a este assunto, evidenciando um aumento da actividade do sistema de defesa antioxidante muscular após um programa de treino físico $(84,117)$. Importa salientar que esta maior capacidade antioxidante não se faz sentir apenas durante os momentos de exercício físico agudo, estando presente durante todas as restantes horas do dia onde a actividade contráctil muscular é mais reduzida (Figuras 12 e 13). Talvez este facto explique a maior longevidade demonstrada nos animais treinados, provavelmente pela maior atenuação das lesões oxidativas normalmente induzidas pelo metabolismo basal das células $(65,86)$. Este aumento da capacidade de defesa contra as ERO não se faz sentir apenas no músculo esquelético, estando presente em numerosos órgãos e tecidos. Por exemplo, em indivíduos treinados, comparativamente aos sedentários, está descrita uma maior capacidade antioxidante no plasma(22, 94) e nos eritrócitos(106). Em animais, tem sido demonstrado que o coração, o fígado e o pulmão evidenciam também melhorias na sua capacidade anti-oxidante após treino físico (8, 10, 17, 117). 


\begin{abstract}
Mecanismos
não-enzimáticos

Conforme já referido, para além das enzimas antioxidantes, os organismos aeróbios possuem outras substâncias antioxidantes não enzimáticas, umas de características lipofílicas (Vitamina E, b-carotenos, ubiquinona e ubiquinol e flavonóides) e outras hidrofílicas
\end{abstract} (Vitamina C e GSH) ${ }^{(41}$, $51,61,62)$. Todas as referidas actuam por intercepção das ERO (Tabela $1)$, convertendo-as em espécies menos reactivas, e participam na reparação das alterações estruturais da célula, iniciadas pelas ERO, contribuindo em conjunto com os outros agentes antioxidantes, para a manutenção do equilíbrio do estado redox da célula (Figura 11)(108,118). Outros agentes antioxidantes não enzimáticos, também referidos na tabela 1, actuam por prevenção, evitando a presença de metais de transição na sua forma livre (prevenindo a ocorrência de reacções de Fenton e de HaberWeiss). Para além destes compostos, também os estrogénios parecem aumentar a capacidade celular de resistência à formação de ERO, funcionando de uma forma cooperativa entre si, embora independente dos restantes antioxidantes $(11,69,118)$.

Em consequência do exercício físico agudo, é de esperar que muitos dos antioxidantes de intercepção diminuam as suas concentrações musculares. Por exemplo, a nível muscular esquelético, numerosos trabalhos têm analisado as concentrações de GSH e de antioxidantes de intercepção exógenos (vitaminas) no músculo esquelético após exercício físico agudo (para refs. ver 61, 66). Assim, no músculo esquelético, a demonstração de uma acentuada redução das concentrações de GSH (com a concomitante elevação das concentrações de GSSG) assim como uma redução dos níveis de vitamina E tecidual, comparativa- mente à situação de repouso, constituem bons indicadores dos níveis de stress oxidativo surgido durante e/ou logo após o exercício(12).

\section{STRESS OXIDATIVO}

Por definição, a situação de stress oxidativo (SO) ocorre quando existe um desequilíbrio entre a acção dos agentes oxidantes e dos antioxidantes, a favor dos primeiros (Figura 12)(43, 46, 50, 85, 102, 104, 109, 110, 119). Em termos gerais, o estado de SO orgânico parece variar com a concentração de oxigénio envolvente, com o tipo de tecido analisado e com o seu estado fisiológico (incluindo aqui as situações de repouso e de exercício físico agudo), com a dieta e a idade do indivíduo, com a ingestão de fármacos, com a exposição a condições ambientais impróprias, tais como radiação ultra violeta, a poluição, a humidade relativa e a temperatura ambiente e com o stress emocional(80).

Esta situação de SO traduz-se, de forma imediata, na incapacidade de impedir ou reparar as repercussões nefastas das ERO sobre as estruturas celulares e é assumido que ocorra em todos os seres biológicos, mesmo em situações de funcionalidade basal, isto é, em repouso (Figura 12)(86). Aumentos do SO podem dever-se não só a um aumento da taxa de produção 


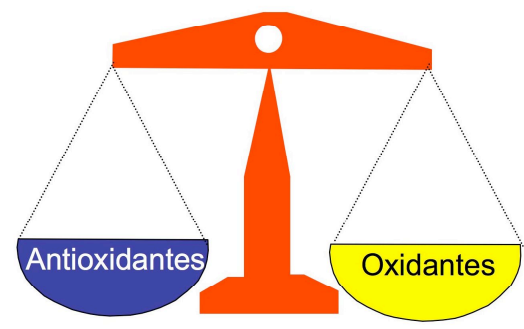

Ausência de stress oxidativo

(não existe em situações fisiológicas)

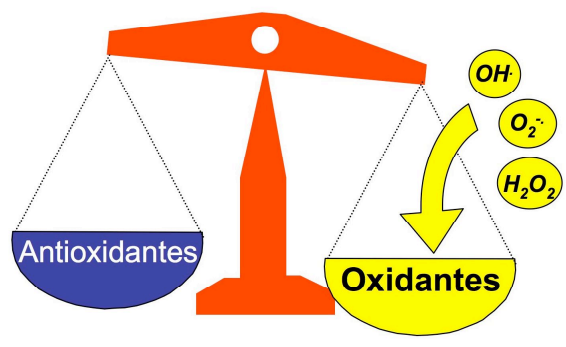

Stress oxidativo

(presente em situação basal)

Figura 12. Conceito de stress oxidativo baseado no desequilíbrio entre as acções pró-oxidante e antioxidante teciduais.

de ERO, mas também a uma redução da capacidade antioxidante ou, ainda, à conjugação destes dois factores $(16,104)$.

No que diz respeito ao músculo esquelético, tendo em consideração que este parece ser muito mais dependente da GSH para a neutralização das ERO do que o fígado e o rim( ${ }^{(9)}$, a medição das concentrações de GSH e GSSG e/ou da actividade das enzimas relacionadas com a sua homeostasia, é considerada o melhor meio de quantificação indirecta do SO neste tecido(62, 63, 109). Apesar dos marcadores utilizados nem sempre revelarem alterações significativas após exercícios suaves (habituais) (para refs. ver 107, 108, 119), a grande maioria dos trabalhos efectuados tem relatado um incremento dos indicadores de stress e de lesão oxidativa no músculo esquelético durante ou após o exercício físico intenso, quer em animais(95), quer em humanos(13), estando a magnitude do fenómeno intimamente dependente das características do exercício efectuado(107).

\section{REPERCUSSÕES OXIDATIVAS SISTÉMICAS DO EXERCÍCIO AGUDO}

Em humanos, por razões éticas e logísticas, associadas aos necessários métodos invasivos, as evidências de stress e de lesão oxidativa motivados pelo exercício agudo têm sido essencialmente estudadas a nível sanguíneo, quer no plasma, quer nas células circulantes $(27,39,89)$. A ocorrência de lesão oxidativa no organismo em geral, particularmente de peroxidação lipídica, foi também testemunhada em humanos com indicadores indirectos obtidos por meios não invasivos de fiabilidade duvidosa, tais como a quantificação da excreção pulmonar de hidrocarbonetos facto, o miocárdio parece ser particularmente susceptível a todas as situações que promovam uma elevação do seu metabolismo, nas quais se incluem o exercício físico agudo, uma vez que a sua capacidade metabólica oxidativa é muito elevada e, simultaneamente, possui uma actividade relativamente baixa das enzimas que compõe o seu sistema antioxidante ${ }^{(17,64)}$. De facto, existem evidências directas de que o exercício agudo aumenta de forma significativa, comparativamente às situações de repouso, a taxa de produção do radical hidroxilo neste órgão(93). Os dados existentes sugerem que as principais fontes desta taxa aumentada de ERO no coração são semelhantes às do músculo esquelético: a mitocôndria e a xantina oxidase(para mais refs. ver 17,64). Para além do músculo esquelético e do coração, a elevação dos níveis de SO e de lesão oxidativa têm também sido descritas em muitos outros órgãos e tecidos $(8,10,17,20,22,29,67,68,78,92,93)$. Esta situação não será de estranhar se tiver em consideração que, durante o exercício físico agudo, as alterações metabólicas não se restringem apenas ao sistema muscular esquelético ou ao sistema cardiovascular ${ }^{7}$, $29,67,68,89,92,99,117)$. De facto, as acentuadas alterações hormonais, assim como as alterações térmicas, associadas ao exercício intenso e exaustivo far-se-ão sentir, de forma mais ou menos intensa, na maior parte das células corporais, tais como no pulmão, no rim e no fígado $(8,10,17,29,67,78,92,93)$.

\section{CONCLUSÕES}

Pelo exposto, não parece haver dúvidas que a realização de exercício físico agudo, especialmente se exaustivo e inabitual, agrava os níveis de $\mathrm{SO}$, quer nos músculos esqueléticos recrutados, quer nos dife- 


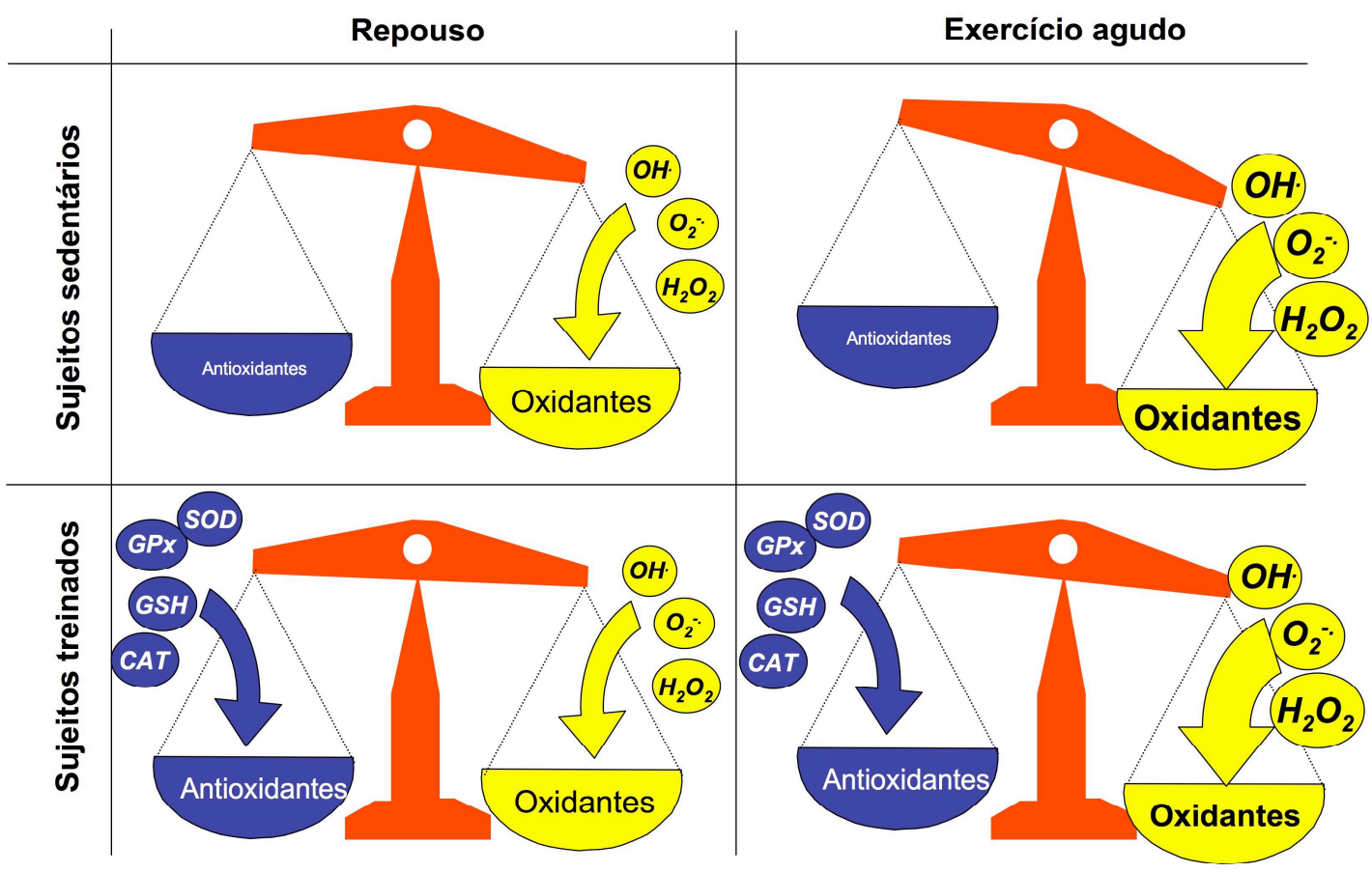

Figura 13. Comparação dos níveis de stress oxidativo entre indivíduos sedentários e treinados, em situações de repouso e de exercício físico agudo.

rentes órgãos e tecidos associados com a regulação da homeostasia orgânica. A magnitude deste processo está intimamente dependente da duração, da intensidade e do tipo de exercício efectuado. Por outro lado, o exercício físico quando praticado de forma regular induz um aumento crónico da actividade do sistema de defesa antioxidante, protegendo o músculo esquelético do ataque das ERO, quer em situações de repouso, quer durante o exercício agudo. Pelo facto de, no dia-a-dia dos atletas, o tempo passado em situações basais ser manifestamente superior aquele dispendido em exercício agudo, é possível que, pelo aumento dos sistemas de defesa antioxidante, os níveis basais de SO nestes sujeitos sejam bem mais reduzidos do que nos sedentários, dando-lhes assim mais protecção contra os processos degenerativos decorrentes do seu próprio metabolismo basal, os quais estão intimamente associados ao processo de envelhecimento biológico. Esta hipótese é suportada pelo aumento da longevidade observado em animais treinados, sujeitos ou não à restrição calórica.

\section{CORRESPONDÊNCIA}

José Alberto Duarte

CIAFEL, FADEUP

R. Dr. Plácido Costa, 91

4200-450 Porto

Tel: 225074784; Fax: 225500689

e-mail: jarduarte@fade.up.pt 


\section{BIBLIOGRAFIA}

1. Agostinelli E, Arancia G, Vedova L, Belli F, Marra M, Salvi $\mathrm{M}$, Toninello A (2004). The biological functions of polyamine oxidation products by amine oxidases: perspectives of clinical applications. Amino Acids. 27: 347-358.

2. Ames B, Shigenaga M, Hagen T (1993). Oxidants, antioxidants, and the degenerative diseases of aging. Proc Natl Acad Sci USA. 90(17): 7915-7922.

3. Appell HJ, Duarte JA, Glöser S, Remião F, Carvalho F, Bastos M, Soares J. (1997). Administration of tourniquet. II. Prevention of postischemic oxidative stress can reduce muscle edema. Arch Orthop Trauma Surg. 116(1-2): 101-105.

4. Appell HJ, Soares J, Duarte JA (1992). Exercise, muscle damage and fatigue. Sports Med. 13(2): 108-115.

5. Arai M, Imai H, Koumura T, Yoshida M, Emoto K, Umeda M, Chiba M, Nakagawa Y (1999). Mitochondrial phospholipid hydroperoxide glutathione peroxidase plays a major role in preventing oxidative injury to cells. J Biol Chem. 274(8): 4924-4933.

6. Armstrong RB, Warren GL, Warren JA (1991). Mechanisms of exercise-induced muscle fibre injury. Sports Med. 12(3): 184-207.

7. Asami S, Hirano T, Yamaguchi R, Itoh H, Kasai H (1998). Reduction of 8-hydroxyguanine in human leukocyte DNA by physical exercise. Free Radic Res. 29(6): 581-584.

8. Asami S, Hirano T, Yamaguchi R, Tsurudome Y, Itoh H, Kasai H (1998). Effects of forced and spontaneous exercise on 8-hydroxydeoxyguanosine levels in rat organs. Biochem Biophys Res Commun. 243(3): 678-682.

9. Asayama K, Kato K (1990). Oxidative muscular injury and its relevance to hyperthyroidism. Free Radic Biol Med. 8(3): 293-303.

10. Aydin C, Ince E, Koparan S, Cangul I, Naziroglu M, Ak F (2005). Protective effects of long term dietary restriction on swimming exercise-induced oxidative stress in liver, heart and kidney of rat. Cell Biochem Funct. 25: 129-137.

11. Baba T, Shimizu T, Suzuki Y, Ogawara M, Isono K, Koseki H, Kurosawa H, Shirasawa T (2005). Estrogen, insulin, and dietary signals cooperatively regulate longevity signals to enhance resistance to oxidative stress in mice. J Biol Chem. 280(16): 16417-16426.

12. Bachur JA, Garcia SB, Vannucchi H, Jordao AA, Chiarello PG, Zucoloto S (2007). Anti-oxidative systems in rat skeletal muscle after acute physical exercise. Appl Physiol Nutr Metab. 32(2):190-196.

13. Bailey DM, Lawrenson L, McEneny J, Young IS, James PE, Jackson SK, Henry RR, Mathieu-Costello O, McCord JM, Richardson RS (2007). Electron paramagnetic spectroscopic evidence of exercise-induced free radical accumulation in human skeletal muscle. Free Radic Res. 41(2): 182-190.

14. Banerjee A, Mandal A, Chandra D, Chakraborti (2003). Oxidant, antioxidant and physical exercise. Molec Cell Biochem. 253(1-2): 307-312.

15. Beckman K, Ames B (1998). The free radical theory of aging matures. Physiol Rev. 78(2): 547-581.

16. Bejma J, Ji L (1999). Aging and acute exercise enhance free radical generation in rat skeletal muscle. J Appl Physiol. 87(1): 465-470.

17. Bejma J, Ramires P, Ji L (2000). Free radical generation and oxidative stress with ageing and exercise: differential effects in the myocardium and liver. Acta Physiol Scand. 169(4): 343-351.
18. Booth FW, Chakravarthy MV, Gordon SE, Spangenburg EE (2002). Waging war on physical inactivity: using modern molecular ammunition against an ancient enemy. J Appl Physiol. 93(1): 3-30.

19. Carreras MC, Poderoso JJ (2007). Mitochondrial nitric oxide in the signaling of cell integrated responses. $\mathrm{Am} \mathrm{J}$ Physiol. 292(5): C1569-C1580.

20. Chevion S, Moran D, Heled Y, Shani Y, Regev G, Abbou B, Berenshtein E, Stadtman E, Epstein Y (2003). Plasma antioxidant status and cell injury after severe physical exercise. Proc Natl Acad Sci USA, 100(9): 5119-5123.

21. Child R, Brown S, Day S, Donnelly A, Roper H, Saxton J (1999). Changes in indices of antioxidant status, lipid peroxidation and inflammation in human skeletal muscle after eccentric muscle actions. Clin Scien. 96: 105-115.

22. Child R, Wilkinson D, Fallowfield J, Donnelly A (1998). Elevated serum antioxidant capacity and plasma malondialdehyde concentration in response to a simulated halfmarathon run. Med Sci Sports Exerc. 30: 1603-1607.

23. Clarkson P, Hubal M (2002). Exercise-induced muscle damage in humans. Am J Phys Med Rehabil. 81: S52-S69.

24. Clarkson P, Thompson H (2000). Antioxidants: what role do they play in physical activity and health? Am J Clin Nutr. 72: 637S-646S.

25. Criswell D, Powers S, Dodd S, Lawler J, Edwards W (1993). High intensity training-induced changes in skeletal muscle antioxidant enzyme activity. Med Sci Sports Exerc. 25(10): 1135-1140.

26. Cui K, Luo X, Xu K, Ven Murthy MR (2004). Role of oxidative stress in neurodegeneration: recent developments in assay methods for oxidative stress and nutraceutical antioxidants. Prog Neuropsychopharmacol Biol Psychiatry. 28(5): 771-799.

27. Demirbag R, Yilmaz R, Guzel S, Celik H, Kocyigit A, Ozcan E (2006). Effects of treadmill exercise test on oxidative/antioxidative parameters and DNA damage. Anadolu Kardiyol Derg. 6(2):135-140.

28. Di Iorio A, Abate M, Di Renzo D, Russolillo A, Battaglini C, Ripari P, Saggini R, Paganelli R, Abate G (2006). Sarcopenia: age-related skeletal muscle changes from determinants to physical disability. Int J Immunopathol Pharmacol. 19(4): 703-719.

29. Dillard C, Litov R, Savin W, Dumelin E, Tappel A (1978). Effects of exercise, vitamin E, and ozone on pulmonary function and lipid peroxidation. J Appl Physiol. 45(6): 927932.

30. DiMauro S (1999). Exercise intolerance and the mitochondrial respiratory chain. Ital J Neurol Sci. 20: 387-393.

31. Di Meo S, Venditti P (2001). Mitochondria in exerciseinduced oxidative stress. Biol Signals Recept. 10(1-2): 125140.

32. Dröge, W (2002). Free radicals in the physiological controlo of cell function. Physiol Rev. 82: 47-95.

33. Duarte J, Carvalho F, Bastos ML, Soares J, Appell HJ (1994). Do invading leucocytes contribute to the decrease in glutathione concentrations indicating oxidative stress in exercised muscle, or are they important for its recovery? Eur J Appl Physiol. 68(1): 48-53.

34. Duarte J, Appell HJ, Carvalho F, Bastos ML, Soares J (1993). Endothelium-derived oxidative stress may contribute to exercise-induced muscle damage. Int J Sports Med. 14(8): 440-443. 
35. Duarte JA, Carvalho F, Fernandes E, Remião F, Bastos ML Magalhães J, Appell H (2004). D-Amphetamine-induced hydrogen peroxide production in skeletal muscle is modulated by Monoamine Oxidase inhibition. Int J Sports Med. 25: 446-449.

36. Duarte J, Leão A, Magalhães J, Ascensão A, Bastos M, Amado F, Vilarinho L, Quelhas D, Appell HJ, Carvalho F (2005). Strenuous exercise aggravates MDMA-induced skeletal muscle damage in mice. Toxicology. 206(3): 349358.

37. Dudley RW, Danialou G, Govindaraju K, Lands L, Eidelman DE, Petrof BJ (2006). Sarcolemmal damage in dystrophin deficiency is modulated by synergistic interactions between mechanical and oxidative/nitrosative stresses. Am J Pathol. 168(4): 1276-1287.

38. Evans, W. (2000). Vitamin E, vitamin C, and exercise. Am J Clin Nutr. 72: 647S-657S

39. Fehrenbach E, Niess AM, Veith R, Dickhuth $\mathrm{HH}$, Northoff $\mathrm{H}$ (2001). Changes of HSP72-expression in leukocytes are associated with adaptation to exercise under conditions of high environmental temperature. J Leukoc Biol. 69(5): 747-754.

40. Fielding R, Manfredi T, Ding W, Fiatarone M, Evans W, Cannon J (1993). Acute phase response in exercise. III. Neutrophil and IL-1 beta accumulation in skeletal muscle. Am J Physiol. 265(1 Pt 2): R166-R172.

41. Finaud J, Lac G, Filaire E (2006). Oxidative stress: relationship with exercise and training. Sports Med. 36(4): 327358.

42. Fornai F, Lenzi P, Frenzilli G, Gesi M, Ferruci M, Lazzeri G Biagioni F, Nigro M, Falleni A, Giusiani M, Pellegrini A, Blandini F, Ruggieri S, Paparelli A (2004). DNA damage and ubiquitinated neuronal inclusions in the substantia nigra and striatium of mice following MDMA (ecstasy). Psychopharmacol. 173: 353-363.

43. Frei B (1999). Molecular and biological mechanisms of antioxidant action. FASEB J. 13(9): 963-964.

44. Fridrovich I (1995). Superoxide radical and superoxide dismutases. Ann Rev Biochem. 64: 97-112.

45. Gassen M, Lamensdorf I, Armony T, Finberg J, Youdim M (2003). Attenuation of methamphetamine induced dopaminergic neurotoxicity by flupirtine: microdialysis study on dopamine release and free radical generation. J Neural Transm. 110: 171-182.

46. Gastell P, Alejo J (2000). Métodos para medir el daño oxidativo. Rev Cub Med Militar. 29(3): 192-198.

47. Gissel H, Clausen T (2001). Excitation-induced Ca2+ influx and skeletal muscle cell damage. Acta Physiol Scand. 171: 327-334.

48. Goldfarb A (1999). Nutritional antioxidants as therapeutic and preventive modalities in exercise-induced muscle damage. Can J Appl Physiol. 24, 3: 249-266.

49. Gomez-Cabrera M, Borrás C, Pallardó F, Sastre J, Ji L, Viña J (2005). Decreasing xanthine oxidase-mediated oxidative stress prevents useful cellular adaptations to exercise in rats. J Physiol. 567(Pt 1): 113-120.

50. Guerrero N, Ruiz M, Barberena E, Dehesa A, Fainstein M (2003). Daño al ADN y niveles de radicales librés en fibroblastos de ratones jóvenes y viejos. Rev Cub Investig Biomed. 22(2): 109-116.

51. Halliwell B (1991). Reactive oxygen species in living systems: source, biochemistry, and role in human disease. $A m$ J Med. 91 (suppl 3C): 14S-22S.
52. Harman D (1991). The aging process: major risk factor for disease and death. Proc Natl Acad Sci USA. 88(12): 5360-5363.

53. Harman D (2003). The free radical theory of aging. Antioxid Redox Signal. 5(5): 557-561.

54. Hellesten Y (2000). The role of xantina oxidase in exercise. In: Sen C, Packer L, \& Hanninen O (Eds.) Handbook of Oxidants and Antioxidants in Exercise. Basel: Elsevier Science. pp: 153-176.

55. Hellsten Y, Richter E, Kiens B, Bangsbo J (1999). AMP deamination and purine exchange in human skeletal muscle during and after intense exercise. J Physiol. 520 (3): 909-920.

56. Hii CS, Ferrante A (2007). Regulation of the NADPH oxidase activity and anti-microbial function of neutrophils by arachidonic acid. Arch Immunol Ther Exp. 55(2): 99-110.

57. Ho Y, Xiong Y, Ma W, Spector A, Ho D (2004). Mice lacking catalase develop normally but show differential sensitivity to oxidant tissue injury. J Biol Chem. 279(31): 3280432812 .

58. Ide T, Tsutsui $\mathrm{H}$, Kinugawa $\mathrm{S}$, Utsumi $\mathrm{H}$, Kang D, Hattori N, Uchida K, Arimura K, Egashira K, Takeshita A (1999). Mitochondrial electron transport complex I is a potential source of oxygen free radicals in the failing myocardium. Circul Res. 15: 357-363.

59. Jackson M (1996). Oxygen radical production and muscle damage during running exercise. In: Marconnet P, Saltin B, Komi P, Poortmans (Eds.) Human Muscular Function During Dynamic Exercise. Bassel: Karger. pp: 121-133.

60. Jayanthi S, Ladenheim B, Andrews A, Cadet J (1999). Overexpression of human copper/zinc Superoxide Dismutase in transgenic mice attenuates oxidative stress caused by methylenedioxymethamphetamine (Ecstasy). Neuroscience. 91(4): 1379-1387.

61. Jenkins RR (1988). Free radical chemistry. Relationship to exercise. Sports Med. 5(3): 156-170.

62. Ji LL (1995). Exercise and oxidative stress: role of the cellular antioxidant systems. Exerc Sport Sci Rev. 23: 135-166.

63. Ji L (1999). Antioxidants and oxidative stress in exercise. Proc Soc Exp Biol Med. 222: 283-292.

64. Ji L (2000) Exercise-induced oxidative stress in the heart. In: Sen CK, Packer L, Hanninen O editors. Handbook of oxidants and antioxidants in exercise. Basel: Elsevier B.V. p. $689-712$

65. Ji LL (2002) Exercise-induced modulation of antioxidant defense. Ann N Y Acad Sci. 959: 82-92.

66. Ji LL, Gomez-Cabrera MC, Vina J (2006). Exercise and hormesis: activation of cellular antioxidant signaling pathway. Ann N Y Acad Sci. 1067: 425-435.

67. Karanth J, Jeevaratnam K (2005). Oxidative stress and antioxidant status in rat blood, liver and muscle: effect of dietary lipid, carnitine and exercise. Int J Vitam Nutr Res. 75(5): 333-339.

68. Kayatekin B, Gönenç S, Açikgöz O, Uysal N, Dayi A (2002). Effects of sprint exercise on oxidative stress in skeletal muscle and liver. Eur J Appl Physiol. 87(2): 141-144.

69. Kita T, Wagner G, Nakashima T (2003). Current research on methamphetamine-induced neurotoxicity: animals models of monoamine disruption. J Pharmacol Sci. 92: 178-195.

70. Lambertucci R, Leveda-Pires A, Rossoni L, Pithon-Curi T (2007) Effects of aerobic exercise training on antioxidant enzyme activities and mRNA levels in soleus muscle from young and aged rats. Mech Aging Develop. 128(3): 267-275. 
71. Laughlin M, Simpson T, Sexton W, Brown O, Smith J, Korthuis R (1990). Skeletal muscle oxidative capacity, antioxidant enzymes, and exercise training. J Appl Physiol. 68(6): 2337-2343

72. Lawler J, Powers S (1999). Oxidative stress, antioxidant status, and the contracting diaphragm. Can J Appl Physiol. 23(1): 23-55.

73. Leaf D, Kleinman M, Hamilton M, Barstow T (1997). The effect of exercise intensity on lipid peroxidation. Med Sci Sports Exerc. 29: 1036-1039.

74. Lee J, Koo N, Min DB (2004). Reactive oxygen species, aging, and antioxidative nutraceuticals. Compre Rev Food Sci Food Safety. 3: 21-33.

75. Lees SJ, Booth FW (2005). Physical inactivity is a disease. World Rev Nutr Diet. 95: 73-79.

76. Leeuwenburgh C, Heinecke J (2001). Oxidative stress and antioxidants in exercise. Curr Med Chem. 8(7): 829-838.

77. Leeuwenburgh C, Ji L (1996). Alteration of glutathione and antioxidant status with exercise in unfed and refed rats. J Nutr. 126(7): 1833-1843.

78. Lew H, Pyke S, Quintanilha A (1985). Changes in the glutathione status of plasma, liver and muscle following exhaustive exercise in rats. FEBS Lett. 185(2): 262-266.

79. Lieber R, Fridén J (2002). Mechanisms of muscle injury gleaned from animals models. Am J Phys Med Rehab. 81: S70-S79.

80. Liu J, Yeo HC, Overvik-Douki E, Hagen T, Doniger SJ, Chu DW, Brooks GA, Ames BN (2000). Chronically and acutely exercised rats: biomarkers of oxidative stress and endogenous antioxidants. J Appl Physiol. 89: 21-28.

81. Luhová L, Lebeda A, Hedererová D, Peê P (2003). Activities of amine oxidase, peroxidase and catalase in seedlings of Pisum Sativum L. under different light conditions. Plant Soil Environ. 49(4): 151-157.

82. McArdle A, Pattwell D, Vasilaki A, Griffiths R, Jackson J (2001). Contractile activity-induced oxidative stress: cellular origin and adaptive responses. Am J Physiol. 280: C621C627.

83. McLoughlin T, Mylona E, Hornberger T, Esser K, Pizza F (2003) Inflammatory cells in rat skeletal muscle are elevated after electrically stimulated contractions. J Appl Physiol. 94(3): 876-882.

84. Metin G, Atukeren P, Alturfan A, Gülyasar T, Kaya M, Gümüstas M (2003). Lipid peroxidation, erythrocyte Superoxide-Dismutase activity and trace metals in young male footballers. Yonsei Med J. 44(6): 979-986.

85. Morel Y, Barouki R (1999). Repression of gene expression by oxidative stress. Biochem J. 342: 481-496.

86. Mota MP, Figueiredo P, Duarte JA (2004). Teorias biológicas do envelhecimento. Rev Port Ciênc Desp. 4(1): 81-110.

87. Muller F, Liu Y, Van Remmen H (2004). Complex III releases superoxide to both sides of the inner mitochondrial membrane. J Biol Chem. 279(47): 49064-49073.

88. Nakamura K, Yamagishi S, Yoshida T, Matsui T, Imaizumi T, Inoue H, Sata M (2007). Hydrogen peroxide stimulates pigment epithelium-derived factor gene and protein expression in the human hepatocyte cell line OUMS-29. J Int Med Res. 35(3): 427-432.

89. Niess A, Hartmann A, Grünert-Fuchs M, Poch B, Speit G (1996). DNA damage after exhaustive treadmill running in trained and untrained men. Int J Sports Med. 72(2): 549554.
90. Nosaka K, Newton M (2002). Concentric or eccentric training effect on eccentric exercise-induced muscle damage. Med Sci Sports Exerc. 34(1): 63-69.

91. Obata T (2002). Dopamine efflux by MPTP and hydroxyl radical generation. J Neural Transm. 109: 1159-1180.

92. Ogonovszky H, Sasvári M, Dosek A, Berkes I, Kaneko T, Tahara S, Nakamoto H, Goto S, Radák Z (2005). The effects of moderate, strenuous, and overtraining on oxidative stress markers and DNA repair in rat liver. Can J Appl Physiol. 30(2): 186-195.

93. Ohkuwa T, Sato Y, Naoi M (1997). Glutathione status and reactive oxygen generation in tissues of young and old exercised rats. Acta Physiol Scand. 159: 237-244.

94. Oliveira A, Schneider C, Ribeiro J, Deresz L, Barp J, BellóKlein A (2003). Oxidative stress after three different intensities of running. Med Sci Sports Exerc. 35: S367.

95. O'Neill C, Stebbins C, Bonigut S, Halliwell B, Longhurst J (1996). Production of hydroxyl radicals in contracting skeletal muscle of cats. J Appl Physiol. 81(3): 1197-1206.

96. Perez A, Cabral de Oliveira A, Estevez E, Molina A, Prieto J, Alvarez A (2003). Mitochondrial, sarcoplasmic membrane integrity and protein degradation in heart and skeletal muscle in exercised rats. Comp Biochem Physiol C Toxicol Pharmacol. 2: 199-206.

97. Petrova V, Rasheva T, Kujumdzieva A (2002). Catalase enzyme in mitochondria of Saccharomyces cerevisiae. Electron J Biotechnol. 5(1): 29-41.

98. Powers S, Criswell D, Lawler J, Ji L, Martin D, Herb R, Dudley G (1994). Influence of exercise and fiber type on antioxidant enzyme activity in rat skeletal muscle. $\mathrm{Am} \mathrm{J}$ Physiol. 266: R375-R380.

99. Powers S, Howley E (2001). Exercise Physiology: Theory and Application to Fitness and Performance. Fourth Ed., McGraw Hill, New York.

100. Powers S, Leeuwenburgh C (1999). Exercise traininginduced alterations in skeletal muscle antioxidant capacity: a brief review. Med Sci Sports Exerc. 31(7): 987-997.

101. Powers S, Lennon S (1999). Analysis of cellular responses to free radicals: focus on exercise and skeletal muscle. Proc Nutr Soc. 58(4): 1025-1033.

102. Pryor W (1986). Oxy-Radicals and Related Species: Their Formation, Lifetimes, and Reactions. Ann Rev Physiol. 48: 657-667.

103. Radi R (1993). Biological antioxidant systems. Toxicol Ind Health. 9: 53-62.

104. Räisänen S, Lehenkari P, Tasanen M, Rahkila P, Härkönen P, Väänänen (1999). Cronic anhydrase III protects cells from hydrogen peroxide-induced apoptosis. FASEB J. 13: 513-522.

105. Sankarapandi S, Zweier J (1999). Bicarbonate is required for the peroxidase function of $\mathrm{Cu}, \mathrm{Zn}$-superoxide dismutase at physiological pH. J Biol Chem. 274(3): 1226-1232.

106. Selamoglu S, Turgay F, Kayatekin B, Gönenc S, Yslegen C (2000). Aerobic and anaerobic training effects on the antioxidant enzymes of the blood. Acta Physiol Hung. 87(3): 267-273.

107. Sen CK (1995). Oxidants and antioxidants in exercise. $J$ Appl Physiol. 79(3): 675-686.

108. Sen CK (2001). Antioxidants in Exercise Nutrition. Sports Med. 31(13): 891-908.

109. Shan XQ Aw TY, Jones DP (1989). Glutathione-dependent protection against oxidative injury. Pharmacol Ther. 47(1): 61-71. 
110. Sies H (1997). Physiological society symposium: impaired endothelial and smooth muscle cell function in oxidative stress. Oxidative stress: Oxidants and antioxidants. Exp Physiol. 82: 291-295.

111. Smolka M, Zoppi C, Alves A, Silveira L, Marangoni S, Pereira-Da-Silva L, Novello JC, Macedo DV (2000). HSP72 as a complementary protection against oxidative stress induced by exercise in the soleus muscle of rats. Am J Physiol. 279: R1539-R1545.

112. Stadtman E (1993). Oxidation of free amino acids and amino acid residues in proteins by radiolysis and by metalcatalyzed reactions. Ann Rev Biochem. 62: 797-821.

113. Symons JD, Theodossy SJ, Longhurst JC, Stebbins CL (1991). Intramuscular accumulation of prostaglandins during static contraction of the cat triceps surae. J Appl Physiol. 71(5): 1837-1842.

114. Tidball JG, Wehling-Henricks M (2007). The role of free radicals in the pathophysiology of muscular dystrophy. $J$ Appl Physiol. 102(4): 1677-1686.

115. Tonkonogi M, Sahlin K (2002). Physical exercise and mitochondrial function in human skeletal muscle. Exerc Sport Sci Rev. 30(3): 129-137.

116. Vandenburgh HH, Hatfaludy S, Sohar I, Shansky J (1990). Stretch-induced prostaglandins and protein turnover in cultured skeletal muscle. Am J Physiol. 259(2 Pt 1): C232C240.

117. Venditti P, Di Meo S (1997). Effect of training on antioxidant capacity, tissue damage, and endurance of adult male rats. Int J Sports Med. 18(7): 497-502.

118. Viitala P, Newhouse I, LaVoie N, Gottardo C (2004). The effects of antioxidant vitamin supplementation on resistance exercise induced lipid peroxidation in trained and untrained participants. Lipids Health Dis. 3(14): 1-9.

119. Vollaard N, Shearman J, Cooper C (2005). Exercise-induced oxidative stress: myths, realities and physiological relevance. Sports Med. 35(12): 1045-1062.

120. Wang W, Ballatori N (1998). Endogenous glutathione conjugates: occurrence and biological functions. Pharmacol Rev. 50(3): 335-356

121. Watson T, MacDonald-Wicks L, Garg M (2005). Oxidative stress and antioxidants in athletes undertaking regular exercise training. Int J Sport Nutr Exerc Metab. 15(2): 131146.

122. White C, Shelton J, Moellering D, Jo H, Patel R, DarleyUsmar V (2000). Exercise and xantine oxidase in the vasculature: superoxide and nitric oxide interactions. In: Sen C, Packer L \& Hanninen, (Eds.) Handbook of Oxidants and Antioxidants in Exercise. Basel: Elsevier Science. pp: 69-86.

123. Yeldandi A, Rao M, Reddy J (2000). Hydrogen peroxide generation in peroxisome proliferator-induced oncogenesis. Mutat Res. 448(2): 159-177.

124. Yildiz O (2007). Vascular smooth muscle and endothelial functions in aging. Ann N Y Acad Sci. 1100: 353-360.

125. Yu B (1994). Cellular defenses against damage from reactive oxygen species. Physiol Rev. 74(1): 139-162. 